\title{
Poly(3-hexylthiophene): TIPS-pentacene blends aiming transistor applications
}

\author{
Maiza da Silva Ozório *, Gabriel Leonardo Nogueira, Rogério Miranda Morais, Cibely da Silva Martin, \\ Carlos José Leopoldo Constantino, Neri Alves
}

Faculdade de Ciências e Tecnologia, UNESP - Univ Estadual Paulista, Departamento de Física, Presidente Prudente, SP 19060-900, Brazil

\section{A R T I C L E I N F O}

\section{Article history:}

Received 24 December 2015

Received in revised form 28 March 2016

Accepted 12 April 2016

Available online 13 April 2016

\section{Keywords:}

TIPS-pentacene

P3HT

Semiconductor blends

Vertical segregation

Surface treatment

Mobility

OFET

\begin{abstract}
A B S T R A C T
Poly(3-hexylthiophene):6,13-bis(triisopropylsilylethynyl)-pentacene (P3HT:TP) blends with a ratio of 1:1 (wt/wt) were deposited via spin coating on anodized oxide $\left(\mathrm{Al}_{2} \mathrm{O}_{3}\right)$. A phase separation of the compounds was observed, resulting in the formation of crystalline aggregates of TP molecules that segregate vertically on the surface. The form of segregation depends on the oxide surface treatment used. Spectroscopy analysis shows a higher molecular order of P3HT in the blend than for neat film and that TP molecules are also distributed in the polymeric matrix. Regarding the OFET characteristics, charge carrier mobilities of $1.2 \times 10^{-3} \mathrm{~cm}^{2} \mathrm{~V}^{-1} \mathrm{~s}^{-1}$ and $2.0 \times 10^{-3} \mathrm{~cm}^{2} \mathrm{~V}^{-1} \mathrm{~s}^{-1}$ were obtained from devices for untreated and (hexamethyldisilazane) HMDS-treated $\mathrm{Al}_{2} \mathrm{O}_{3}$ gate dielectric, respectively. These results confirm that P3HT:TP blends have good potential as an active layer in organic field effect transistors (OFETs).
\end{abstract}

(c) 2016 Elsevier B.V. All rights reserved.

\section{Introduction}

There are basically two types of organic semiconductors, conjugated polymers and conjugated small molecules. Among the polymeric semiconductors, the poly(3-hexylthiophene) (P3HT), a derivative of thiophene stands out, and among the small conjugated molecules the TIPS-pentacene (TP), a pentacene derivative. The thin film morphology for these semiconductors is influenced by several parameters, such as, deposition method, solvent, evaporation rate and, in particular, the thermal treatment $[1,2]$.

In P3HT, the film structure is formed by interconnected crystalline lamellae embedded in an amorphous matrix. Studies show that the orientation of the lamellar domain is influenced by molecular weight $[3,4]$. In P3HT with low molecular weight, the charge carrier is only highly effective on the lamellar domains, and throughout the film is reduced by the lack of interconnection between the domains. The lamellar domains in high molecular weight films are smaller, allowing best interconnections and, consequently, better mobility [5].

In the case of TP, the mobility depends strongly on the crystal orientation, crystalline domain size, presence of cracks and crystallite thickness, reaching values of $1.8 \mathrm{~cm}^{2} \mathrm{~V}^{-1} \mathrm{~s}^{-1}[6,7]$. These parameters are determined by solvent choice, solution concentration, temperature of thermal treatment, methods of deposition and substrate materials. In

\footnotetext{
* Corresponding author.

E-mail address: ozoriounesp@gmail.com (M. da Silva Ozório).
}

general, high boiling point solvents allow slow crystal growth, forming large lamellar domains making it possible to obtain higher mobility. In these cases, heat treatment with high temperature is required for complete solvent evaporation, but temperatures higher than $60^{\circ} \mathrm{C}$ can crack the film, damaging it [8]. However, TP films prepared by solution show high mobility but its processing is very difficult.

Thin films of TP prepared by spin coating exhibit high crystalline order, which extend over a large area, but for reasons mentioned above, it is not easy to obtain a large number of devices with uniform characteristics. The mobility may vary from $5.0 \times 10^{-4}$ to $2.8 \times 10^{-1} \mathrm{~cm}^{2} \mathrm{~V}^{-1} \mathrm{~s}^{-1}$ depending on the rotation speed [9]. In other deposition techniques, such as inkjet printing or drop casting, the mobility varies from $2.5 \times 10^{-4}$ to $0.24 \mathrm{~cm}^{2} \mathrm{~V}^{-1} \mathrm{~s}^{-1}$ [10]. Then the challenge of making good devices is not easy for any technique. That is to say, the mobility may vary up to three orders of magnitude due to loss of control of crystalline growth.

One possible means of improving the morphology of the TP is to develop polymer blends, in which we can control the grain size, crystallinity of the film and other parameters. One factor that should be considered in blend developing using two semicrystalline materials is the phase segregation in the polymeric matrix. Phase segregation is dependent on the polarity difference between the two components of the mixture, so the crystallization process and crystal orientation can be also influenced by the degree of phase separation between the two constituents. These behaviors can be explained by the theory of FloryHuggins [11]. Thus, the film formation may be dominated by two interaction factors: solvent-solute and solute-solute [12]. In the first case, 


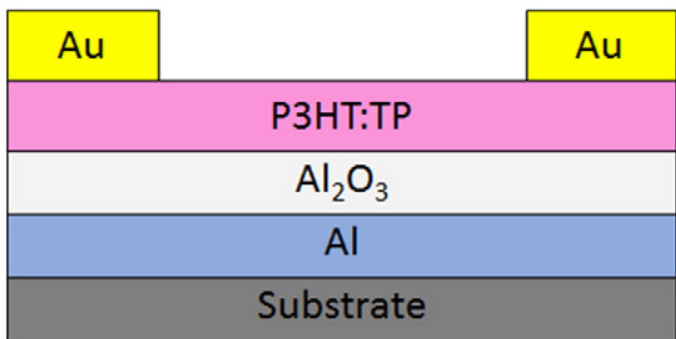

Fig. 1. Bottom-contact top-gate architecture of transistor.

the solvent evaporation in the top surface leads to a higher concentration of the solute, and as result there is a bigger proportion of the more soluble component in this interface and, consequently, a vertical segregation. For the second case, the solidification of the two components affects the film structure, since in the crystallization process, the first part solidified is expelled to the surface.

In this work, we report the study of a blend with P3HT in order to control crystallographic growth of TP and its evaluation for using in organic field effect transistors (OFETs). The aim is to match the properties of each semiconductor in a single device using anodized aluminum oxide $\left(\mathrm{Al}_{2} \mathrm{O}_{3}\right)$ as insulator gate.

\section{Experimental details}

Transistors were manufactured using a bottom-gate top-contact architecture, as shown in Fig. 1. A 200 nm layer of Al was deposited on a glass substrate via thermal evaporation in high vacuum $\left(<10^{-6}\right.$ Torr). Then a layer of $\mathrm{Al}_{2} \mathrm{O}_{3}$ with thickness of $60 \mathrm{~nm}$ was grown by anodization leaving a residual $\mathrm{Al}$ layer to be used as the gate electrode. The surface of the $\mathrm{Al}_{2} \mathrm{O}_{3}$ was treated by immersing it in a solution of hexamethyldisilazane (HMDS) for $30 \mathrm{~min}$ and then rinsed with acetone and dried with nitrogen flow.

P3HT and TP, obtained from Sigma-Aldrich, were dissolved in toluene with a ratio of $1: 1 \mathrm{wt} / \mathrm{wt}$. The solution was filtered using Millex ${ }^{\circledR}$ HV PVDF $0.45 \mu \mathrm{m}$ filters and deposited by spin coating onto $\mathrm{Al}_{2} \mathrm{O}_{3}$ with a constant rotation of $2000 \mathrm{rpm}$ for $60 \mathrm{~s}$ in an inert atmosphere (glovebox). The P3HT:TP films were thermally treated at $100{ }^{\circ} \mathrm{C}$ for $2 \mathrm{~h}$ to remove the solvent, thereby obtaining the semiconductor blend. The transistor was completed by evaporation of source and drain electrodes of $\mathrm{Au}$ in a high vacuum $\left(<10^{-6}\right.$ Torr) using a shadow mask. The length and width channels are $90 \mu \mathrm{m}$ and $3 \mathrm{~mm}$, respectively. P3HT:TP films were characterized morphologically using scanning electron microscopy (SEM) with a Carls Zeiss equipment, EVO LS15 model (Laboratory LabMMEV at FCT/UNESP), and atomic force microscopy (AFM) with a Nanosurf microscope, model easy Scan 2, tip of silicon nitride and tapping mode. Structural analysis was performed by Raman spectroscopy using a Renishaw micro-Raman spectrograph, model inVia, coupled to a Leica optical microscope, which $100 \times$ objective lens allows collecting spectra with ca. $1 \mu \mathrm{m}$ spatial resolution, CCD detector, laser at $633 \mathrm{~nm}$ and 1800 grooves/mm grating with additional edge
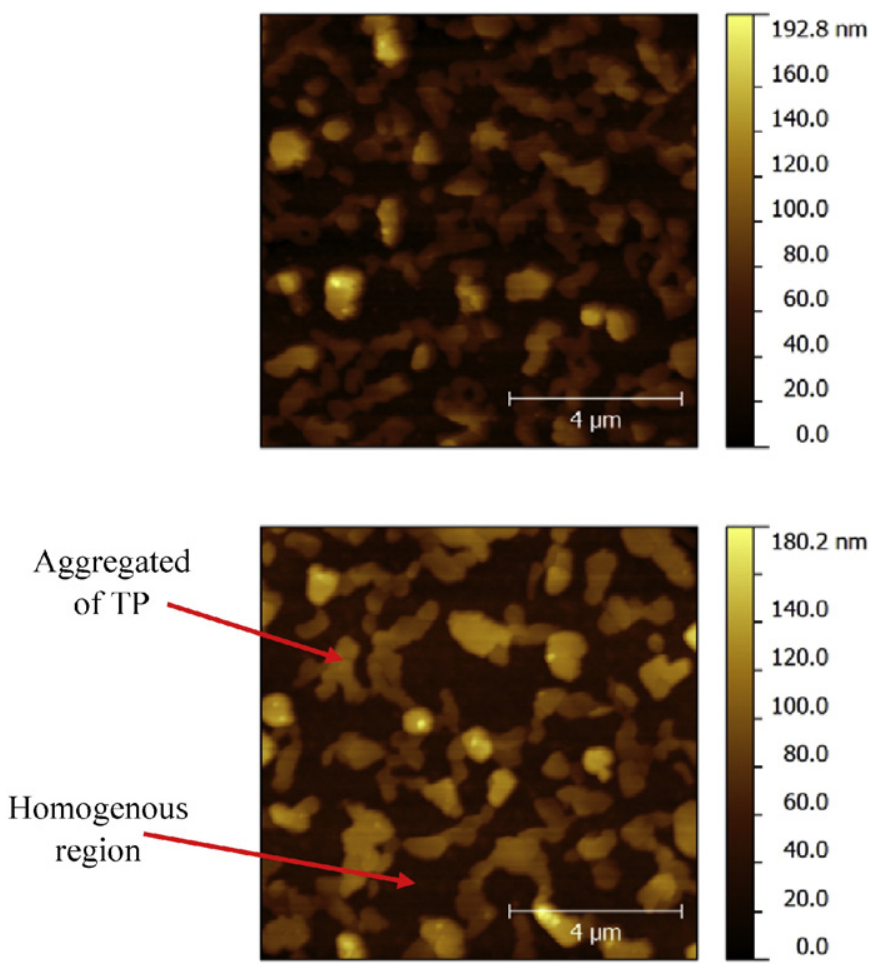

Fig. 3. : AFM topographic images of P3HT:TP films on $\mathrm{Al}_{2} \mathrm{O}_{3}$. (a) Untreated and (b) HMDStreated. The arrows point to aggregates of the TP and homogeneous regions, as indicated. Surface rms roughness of Fig. 3a and $3 b$ are 26.4 and $27.5 \mathrm{~nm}$, respectively. The scanned area is $10 \mu \mathrm{m} \times 10 \mu \mathrm{m}$.

filter leading to a spectral resolution of ca. $4 \mathrm{~cm}^{-1}$, and a computercontrolled three-axis-encoded (XYZ) motorized stage. The transistors $\mathrm{Al} / \mathrm{Al}_{2} \mathrm{O}_{3} / \mathrm{P} 3 \mathrm{HT}$ :TP were electrically characterized by output and transfer curves using a semiconductor characterization system (Keithley 4200 SCS).

\section{Results and discussion}

Fig. 2a and $\mathrm{b}$ shows the surface image of P3HT:TP blends deposited onto $\mathrm{Al}_{2} \mathrm{O}_{3}$, untreated and HMDS-treated, respectively. We can observe a difference in the morphology of surface film deposited on untreated $\mathrm{Al}_{2} \mathrm{O}_{3}$ compared with the treated $\mathrm{Al}_{2} \mathrm{O}_{3}$. A better homogeneity of the blend can be obtained with HMDS-treated oxide and consequently, an improvement of its structural organization. Phase segregation of TP is observed in polymeric matrix of P3HT due to its high crystalline orientation, forming aggregates through $\pi-\pi$ interactions in the surface. However, continuous domain is not formed in the TP phase, i.e., the aggregates are not percolated.

AFM images $(10 \times 10 \mu \mathrm{m})$ of P3HT:TP blend on $\mathrm{Al}_{2} \mathrm{O}_{3}$ untreated and HMDS-treated are shown in Fig. 3a and b, respectively. Films of blend on
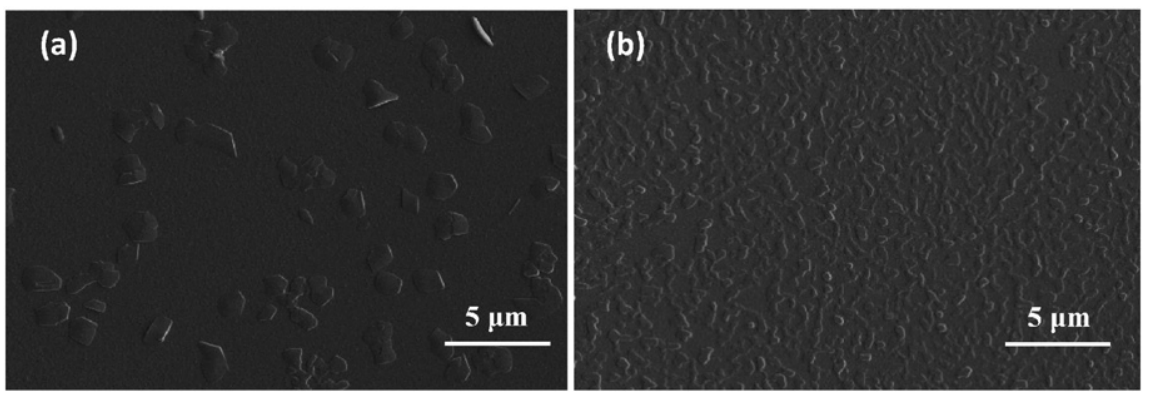

Fig. 2. SEM images of P3HT:TP films on $\mathrm{Al}_{2} \mathrm{O}_{3}$. (a) Untreated and (b) HMDS-treated. Scale bar: $5 \mu \mathrm{m}$. Magnification: 10,000×. 

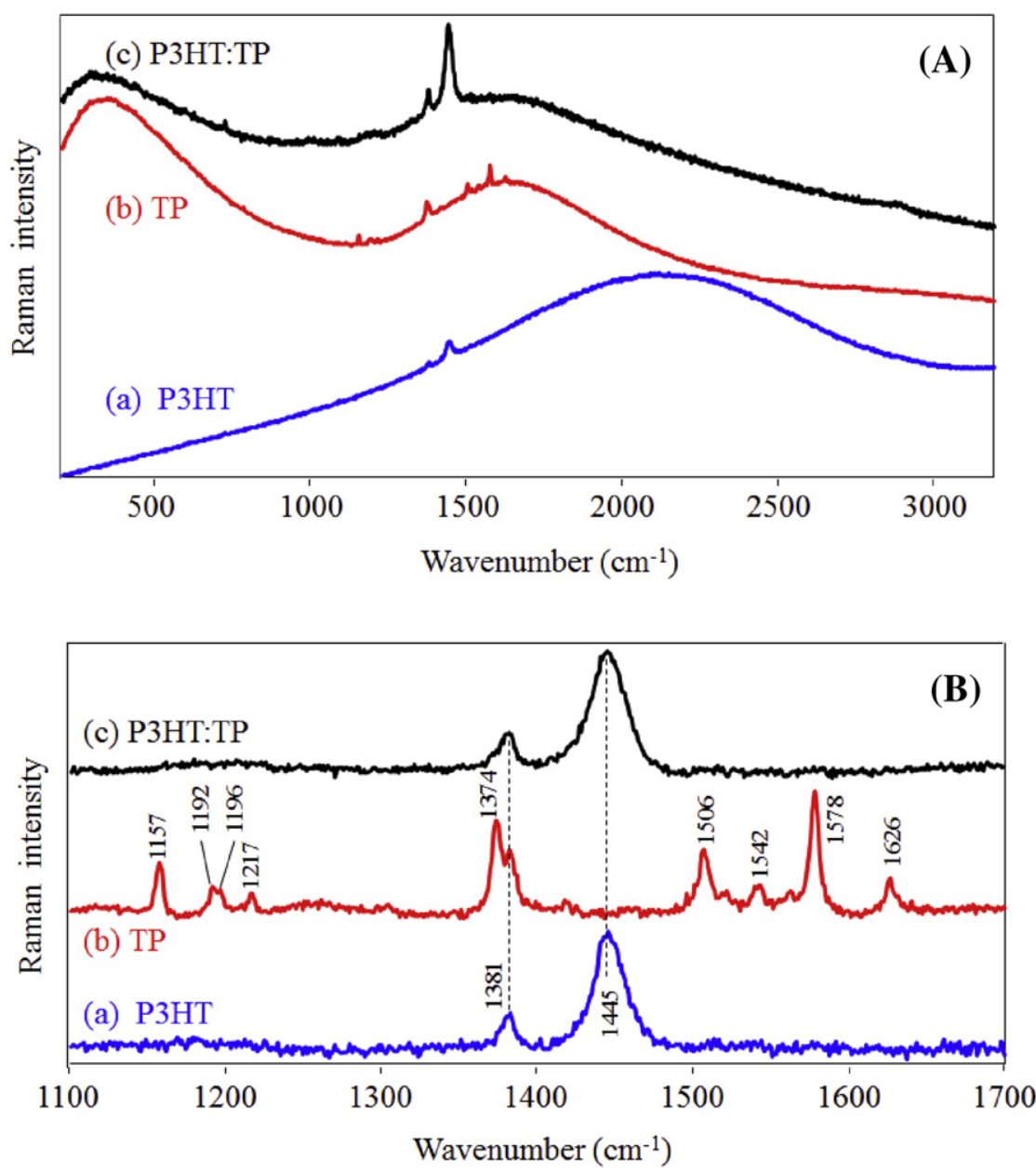

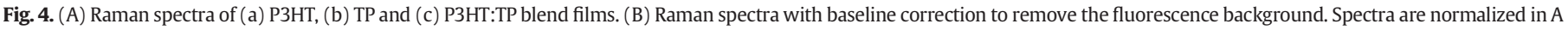
and $B$.

the untreated $\mathrm{Al}_{2} \mathrm{O}_{3}$ showed roughness of ca. $26.4 \mathrm{~nm}$ while the treated one showed $27.5 \mathrm{~nm}$. The thickness of the two films are about $100 \mathrm{~nm}$ and its roughness did not show significant differences meaning that the treatment surface with HMDS does not influence the roughness. The lighter regions in both images are the TP aggregates that are higher, as indicated in Fig. 3b. This morphology is due to vertical segregation of the TP and is similar for other blend ratios.

Fig. 4a shows the Raman spectrum of P3HT film, for which we can observe a broad fluorescence band at shorter wavenumbers and a few vibrational modes between 1200 and $1600 \mathrm{~cm}^{-1}$. The main peak of the P3HT spectrum occurs at $1445 \mathrm{~cm}^{-1}$, that is related to symmetrical stretching of $\mathrm{C}=\mathrm{C}$ bond $[13,14]$. Additionally, there is a peak at $1381 \mathrm{~cm}^{-1}$ corresponding to $\mathrm{C}-\mathrm{C}$ thiophene intraring stretching [14].

The Raman spectrum of the TP (see Fig. 4b) showed two fluorescence bands and several vibrational modes. The peaks at 1157 and $1194 \mathrm{~cm}^{-1}$ are attributed to $\mathrm{C}-\mathrm{H}$ bending from the ends and sides of the pentacene backbone [15]. The peaks at 1374 and $1578 \mathrm{~cm}^{-1}$ are the signature of $\mathrm{C}-\mathrm{C}$ ring stretching modes with the carbon atoms predominantly vibrating along the shorter and longer molecular axis, respectively [16].

The Raman spectrum of the P3HT:TP blend is shown in Fig. 4c, in which the fluorescence bands of the TP and the vibrational bands of

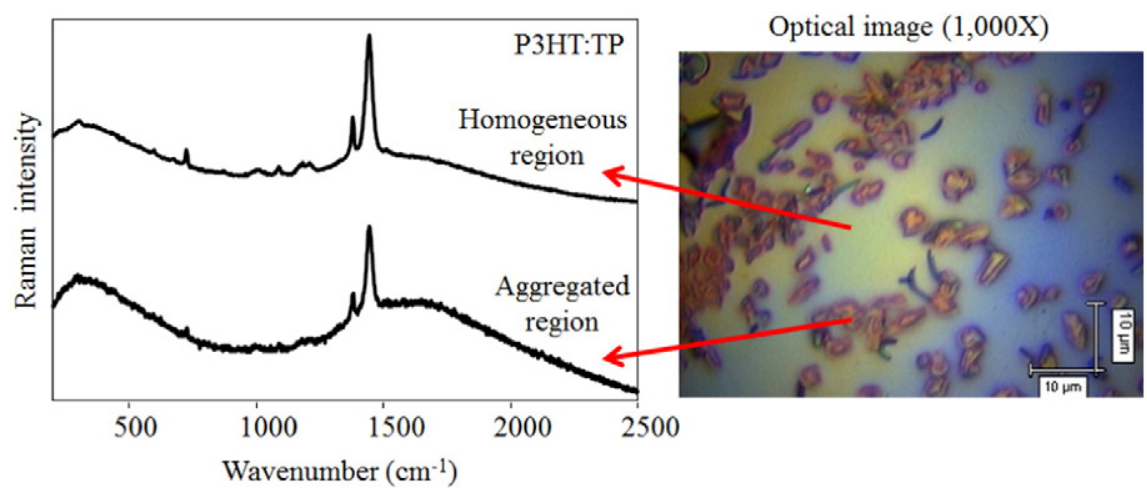

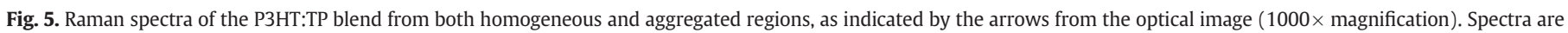
normalized. Laser line at $633 \mathrm{~nm}$ 
the P3HT (1445 and $1381 \mathrm{~cm}^{-1}$ ) are seen, keeping the spectral profile from each component. The $\mathrm{C}=\mathrm{C}$ stretching mode from $\mathrm{P} 3 \mathrm{HT}$ is sensitive to the degree of molecular order of P3HT (molecular $\pi-\pi$ stacking) [14]. Thus, the $A_{C-C} / A_{C}=c$ ratio, being $A_{C-C}$ and $A_{C=C}$ the integrated areas of the $\mathrm{C}-\mathrm{C}$ and $\mathrm{C}=\mathrm{C}$ stretching bands, respectively, can also provide information about the degree of molecular order of P3HT: the higher ratio is due to the higher the molecular order. The $A_{\mathrm{C}-\mathrm{C}} / A_{\mathrm{C}=\mathrm{C}}$ ratio increases from 0.10 to 0.15 from P3HT film to blend P3HT:TP, which indicates that P3HT ordered phase is higher for the blend than for the neat film. The integrated areas were calculated by fitting through mixed Gaussian-Lorentz function.

Taking advantage of the optical microscope coupled to the Raman spectrograph, leading to morphological and chemical information (distribution of the components) at micrometer scale, micro-Raman spectroscopy was performed on the aggregate and on the homogeneous region (around the aggregates) of the P3HT:TP, as shown in Fig. 5. This study was carried out aiming to analyze how the materials are distributed along the film. Both spectra are almost identical, which provides evidence of the existence of the two materials in each region. Besides, the Raman vibrational modes from P3HT ( $\mathrm{C}=\mathrm{C}$ and $\mathrm{C}-\mathrm{C}$ ) at both areas of the film demonstrate comparable $A_{C-C} / A_{C=C}$ ratios ( 0.16 for the homogeneous and 0.15 for the aggregated region). This suggests that the P3HT presents very similar degree of molecular order at both film areas.

In conclusion, we believe that TP is distributed in the volume of the polymeric matrix, although there is a larger amount of the TP in the aggregate in relation to P3HT. TP structures adhere to the volume of the polymeric matrix while the crystalline aggregates segregate vertically,
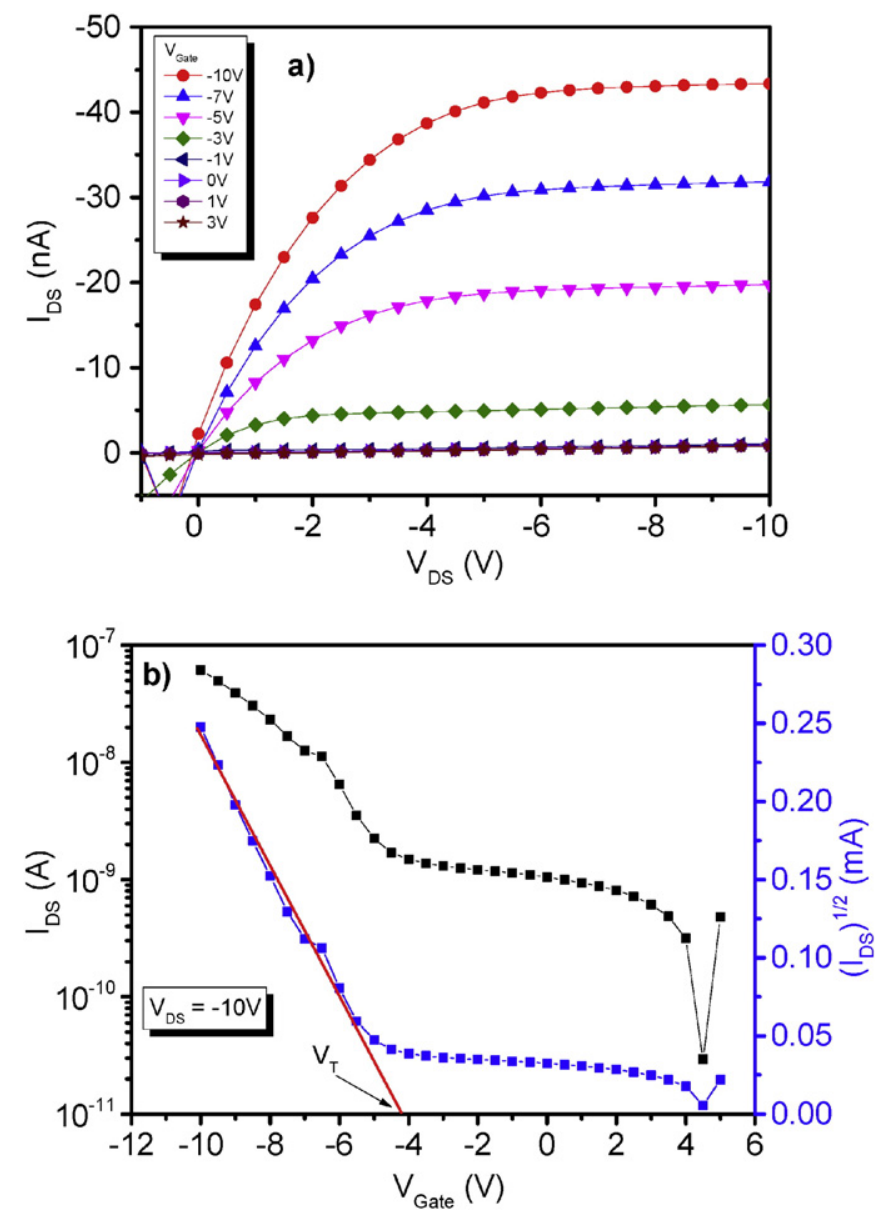

Fig. 6. Output and transfer curves of an OFET with P3HT:TP on untreated $\mathrm{Al}_{2} \mathrm{O}_{3}$. (a) Output curve: $I_{D S}-V_{D S}$ for various values of $V_{G}$ and (b) transfer curve: $I_{D S}-V_{G}$ for $V_{D S}=-10 \mathrm{~V}$ (saturation regime). Mobility is $1.2 \times 10^{-3} \mathrm{~cm}^{2} \mathrm{~V}^{-1} \mathrm{~s}^{-1}$ and threshold voltage $\left(V_{T}\right)$ is $4.2 \mathrm{~V}$. and this depends on the crystal orientation and segregation intensity. The size, shape and number of aggregates depend on the crystallization kinetics, which can be controlled by deposition parameters, solvent, surface characteristics where deposited, deposition temperature and heat treatment [7]. We found that oxide surface treatment is a highly important factor as well as solvent and deposition methods (not shown here). These results point out that more studies could determine the necessary conditions to obtain continuous domain at one surface (up or down), achieving good characteristics for transistor applications.

The output and transfer curves for the transistors manufactured with P3HT:TP blend deposited onto untreated and HMDS-treated aluminum oxide are shown in Figs. 6 and 7, respectively. In both cases, a saturation regime in the output curves is observed (Figs. 6a and 7a) with low operation voltage, which is an important characteristic for application in electronic circuits. The magnitude of the current is in the order of nanoampere $(\mathrm{nA})$. This low value is observed due to the high dielectric constant and surface oxide roughness, besides the fact that the aggregates are not percolated, consistent with microscopic data. Although P3HT:TP blend deposited on the HMDS-treated oxide does not show the percolation either, its output current is bigger.

Figs. $6 \mathrm{~b}$ and $7 \mathrm{~b}$ show the transfer curves for $V_{D S}=-10 \mathrm{~V}$ (saturation regime), which allow calculating the mobility $(\mu)$ and the ratio between the state currents "on" and "off" $\left(I_{\mathrm{on}} / I_{\mathrm{off}}\right)$. The mobility was $1.2 \times 10^{-3} \mathrm{~cm}^{2} \mathrm{~V}^{-1} \mathrm{~s}^{-1}$ and $2.0 \times 10^{-3} \mathrm{~cm}^{2} \mathrm{~V}^{-1} \mathrm{~s}^{-1}$ for the blend on untreated and treated oxides, respectively. The mobility encountered could be bigger if there was percolation of the crystalline domains forming a continuous film along the surface. The ratio $I_{\mathrm{on}} / I_{\text {off }}$ is about $10^{2}$ in both cases. The off current is about $10^{-9} \mathrm{~A}$. This value is quite
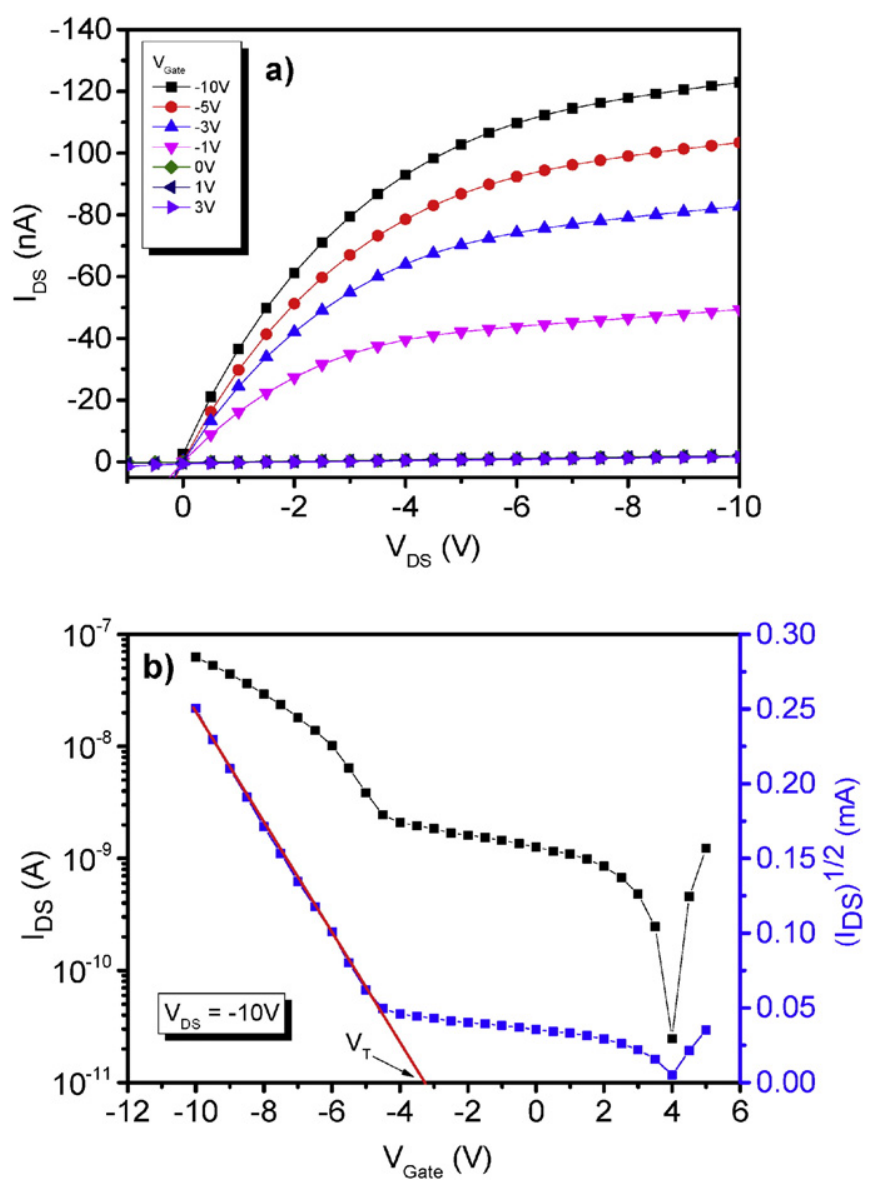

Fig. 7. Output and transfer curves of an OFET with P3HT:TP on HMDS- treated $\mathrm{Al}_{2} \mathrm{O}_{3}$. (a) Output curve: $I_{D S}-V_{D S}$ for various values of $V_{G}$ and (b) transfer curve: $I_{D S}-V_{G}$ for $V_{D S}=-10 \mathrm{~V}$ (saturation regime). Mobility is $2.0 \times 10^{-3} \mathrm{~cm}^{2} \mathrm{~V}^{-1} \mathrm{~s}^{-1}$ and threshold voltage $\left(V_{T}\right)$ is $3.2 \mathrm{~V}$. 
high due to leakages on the oxide, not the conduction in semiconductor blend. The threshold voltage $\left(V_{T}\right)$ was calculated extrapolating the linear region of the straight line on $\left(I_{D S}\right)^{1 / 2}$ versus $V_{G}$ curves when $I_{D S}=0$, obtaining 4.2 and $3.2 \mathrm{~V}$ for untreated and HMDS-treated devices, respectively.

According to Alberto Salleo et al., the lower mobility among the constituents tends to prevail in non-percolated systems. That is, considering the material with greater mobility $\left(\mu_{H}\right)$ in a volume $V_{H}$ and the material with lower mobility $\left(\mu_{L}\right)$ in a volume $V_{L}$, the carriers are moving in random form in both materials. In this way, the mobility of the blend $\left(\mu_{\text {MIX }}\right)$ can be estimated by Eq. (1) [17]:

$\mu_{M I X}=\frac{V \mu_{H} \mu_{L}}{\left[\mu_{H} V_{L}+\mu_{L} V_{H}\right]}$.

Using the relation above, for P3HT:TP blend, we find a mobility of about $10^{-3} \mathrm{~cm}^{2} \mathrm{~V}^{-1} \mathrm{~s}^{-1}$. Which is consistent with our data. It is worth mentioning that this is a qualitative analysis being appropriated for the case where there is no percolation.

\section{Conclusions}

The morphological analysis allows us to infer that the polymeric matrix of P3HT inhibits the crystalline growth of the TP. However, a phase separation of the compounds occurs resulting in the formation of crystalline aggregates that segregates vertically to the surface. Spectroscopy measurements confirm that there is not only TP in the aggregate, indeed a considerable amount of TP is also dispersed in the polymer matrix volume. Besides, the molecular order of the P3HT is higher for the blend than for the neat film. The treatment of the $\mathrm{Al}_{2} \mathrm{O}_{3}$ surface with HMDS showed a strong influence on the formation of the aggregate. Although the transistors of P3HT:TP with $\mathrm{Al}_{2} \mathrm{O}_{3}$ insulator present mobility of around $10^{-3} \mathrm{~cm}^{2} \mathrm{~V}^{-1} \mathrm{~s}^{-1}$ in both untreated and HMDS-treated oxides, the treatment almost doubles the mobility. Thus, the electrical and morphological characteristics, and therefore the device performance, depend strongly on the processing blend. These results demonstrate the viability of using the P3HT:TP blend for application in transistors, confirming its great potential.

\section{Acknowledgments}

The authors thank the Fundação de Amparo à Pesquisa do Estado de São Paulo (FAPESP-Proc. 2014/13015-9) and Coordenação de Aperfeiçoamento do Ensino Superior (CAPES) for financial support.

\section{References}

[1] M.L. Chabinyc, M.F. Toney, R.J. Kline, I. McCulloch, M. Heeney, X-ray scattering study of thin films of poly(2,5-bis(3-alkylthiophen-2-yl)thieno[3,2-b]thiophene), J. Am. Chem. Soc. 129 (2007) 3226-3237.

[2] J. Rivnay, R. Steyrleuthner, L.H. Jimison, A. Casadei, Z.H. Chen, M.F. Toney, A. Facchetti, D. Neher, A. Salleo, Drastic control of texture in a high performance n-type polymeric semiconductor and implications for charge transport, Macromolecules 44 (2011) (5346-5255).

[3] B.S. Ong, Y. Wu, P. Liu, S. Gardner, High-performance semiconducting polythiophenes for organic thin-film transistors, J. Am. Chem. Soc. 126 (2004) 3378-3379.

[4] R.J. Kline, et al., Dependence of regioregular poly(3-hexylthiophene) film morphology and field-effect mobility on molecular weight, Macromolecules 38 (2005) 3312-3319.

[5] L.H. Jimison, et al., Charge-transport anisotropy due to grain boundaries in directionally crystallized thin films of regioregular poly(3-hexylthiophene), Adv. Mater. 21 (2009) 1568-1572.

[6] M.W. Lee, G.S. Ryu, Y.U. Lee, C. Pearson, M.C. Petty, C.K. Song, Control of droplet morphology for inkjet-printed TIPS-pentacene transistors, Microelectron. Eng. 94 (2012) 1-4.

[7] M.B. Madec, P.J. Smith, A. Malandraki, N. Wang, J.G. Korvink, S.G. Yeates, Enhanced reproducibility of inkjet organic thin film transistors based on solution processable polymer-small molecule blends, J. Mater. Chem. 20 (2010) 9155-9160.

[8] H.B. Akkerman, H. Li, Z. Bao, TIPS-pentacene crystalline thin film growth, Org. Electron. 13 (2012) 2056-2062.

[9] K.W. Chou, et al., Late stage crystallization and healing during spin coating enhance carrier transport in small-molecule organic semiconductors, J. Mater. Chem. C 2 (2014) 5681-5689.

[10] C.M. Keum, J.H. Kwon, S.D. Lee, J.H. Bae, Control of the molecular order and cracks of the 6,13-bis(triisopropylsilylethynyl)-pentacene on a polymeric insulator by anisotropic solvent drying, Solid State Electron. 89 (2013) 189-193.

[11] G.H. Fredrickson, A.J. Liu, F.S. Bates, Entropic corrections to the Flory-Huggins theory of polymer blends: architectural and conformational effects, Macromolecules 27 (1994) 2503-2511.

[12] C.M. Bjorstrom, K.O. Magnusson, E. Moons, Control of phase separation in blends of polyfluorene (co)polymers and the C60-derivative PCBM, Synth. Met. 152 (2005) $109-112$.

[13] W.C. Tsoi, et al., The nature of In-plane skeleton Raman modes of P3HT and their correlation to the degree of molecular order in P3HT:PCBM blend thin films, J. Am. Chem. Soc. 133 (2011) 9834-9843.

[14] M. Trznadel, M. Zagórska, M. Lapkowski, G. Louarn, S. Lefrant, A. Pron, UV-VIS-NIR and Raman spectroelectrochemistry of regioregular poly(3-octylthiophene): comparison with its non-regioregular analogue, J. Chem. Soc. Faraday Trans. 92 (1996) 1387-1393.

[15] D.T. James, et al., Thin-film morphology of inkjet-printed single-droplet organic transistors using polarized Raman spectroscopy: effect of blending TIPS-pentacene with insulating polymer, Am. Chem. Soc. 5 (2011) 9824-9835.

[16] J. Xu, et al., Probing the interfacial molecular packing in TIPS-pentacene organic semiconductors by surface enhanced Raman scattering, J. Mater. Chem. C 2 (2014) 2985-2991.

[17] R.A. Street, J.E. Northrup, A. Salleo, Transport in polycrystalline polymer thin-film transistors, Phys. Rev. B 71 (2005) 165202 